\title{
Are we having fun yet? Savoring, Type A behavior, and vacation enjoyment
}

\author{
Jennifer L. Smith • Fred B. Bryant
}

\begin{abstract}
Although studies of Type A behavior ceased in the early 1990s because of failures to replicate its connections with heart disease, the Type A behavior pattern of speed, impatience, perfectionism, drivenness, and hostility may nevertheless be important in understanding individual differences in the subjective quality of life. The present study tested the hypothesis that Type A behavior undermines the enjoyment of leisure time and that this detrimental effect is mediated by savoring responses that hamper enjoyment. Confirming hypotheses, analysis of self-report survey data $(N=764)$ revealed that: (a) higher levels of Type A impatience in social situations predicted significantly less vacation enjoyment; (b) social impatience predicted significantly lower levels of memory building and counting blessings, and higher levels of killjoy thinking, as savoring responses to vacation experiences, which in turn predicted less enjoyment; and (c) variations in these three savoring responses significantly mediated the link between Type A impatience and enjoyment, and together explained $85 \%$ of the total effect of impatience on vacation enjoyment. Furthermore, Type A impatience significantly predicted killjoy thoughts about how one's vacation could have been better, but not kill-joy thoughts about other things one should be doing instead of vacationing, suggesting that A-B differences in dampening savoring responses reflect differences in perfectionism rather than time urgency. Finally, temporal awareness moderated the detrimental impact of Type A impatience on enjoyment, by weakening the negative relationship between impatience and enjoyment. Clearly, Type A behavior has implications for understanding the quality, if not the quantity, of people's lives.
\end{abstract}

Keywords: savoring, Type A behavior, enjoyment, subjective wellbeing, subjective well-being

\section{Introduction}

During the late 1950s, cardiologists (Friedman \& Rosenman, 1959) first proposed that behavior patterns of speed, impatience, perfectionism, drivenness, and hostility increased individuals' vulnerability to heart disease. During the early 1970s, theorists (e.g., Friedman \& Rosenman, 1974) labeled this constellation of traits associated with coronary disease "Type A behavior," and distinguished it from an oppositional counterpart termed "Type B behavior," reflecting a relaxed, easy-going, slower-paced lifestyle. For the next two decades, evidence accumulated linking Type A behavior to an increased risk of coronary artery heart disease (e.g., Haynes, Feinleib, \& Kannel, 1980). However, later research (e.g., Ragland \& Brand, 1988) and subsequent meta-analyses (e.g., Myrtek, 2001) failed to support the association between Type A behavior and heart disease. As a result, work on Type A behavior effectively ended in the early 1990s, and since then little empirical work has examined this construct (Samuel \& McClure, 2002). 
Yet, even if Type A behavior is unrelated to morbidity or mortality, this behavior pattern may still be important because of its potential effect on the subjective quality of people's lives and their levels of enjoyment in response to positive experiences (Bryant \& Yarnold, 1990). Along these lines, theorists have argued that Type A behavior undermines subjective wellbeing and erodes one's capacity to enjoy life (Friedman \& Ulmer, 1984). For example, Friedman and Ulmer (1984) describe Type A behavior as "a continuous struggle, and unremitting attempt to accomplish or achieve more and more things or participate in more and more events in less and less time, frequently in the face of opposition - real or imagined-from other persons" (p. 31). Accordingly, the present study investigated differences in the ways that Type As and Type Bs react to the positive experiences that vacations provide and how these differences ultimately impact the extent to which individuals enjoy their vacations.

A vacation experience, and leisure more broadly, is a dynamic, multiphasic process rather than a static outcome (Clawson \& Knetsch, 1966; Madrigal, 2003; Stewart, 1998). As leisure experiences unfold, antecedent goals and affective expectations shape ongoing appraisaldependent emotional reactions, which in turn shape proximal satisfaction, enjoyment, summary judgments, and future expectations (Madrigal, 2003). In addition, motives, expectations, and preferences shift over time during leisure experiences (Hultsman, 1998; Stewart \& Hull, 1992). As a form of leisure, a vacation may even be conceived as an emerging state of mind rather than as an event, and "as a sequence of transactions between individuals and their environments, as personal stories with temporal and spatial qualities" (Stewart, 1998, p. 391). Moreover, the experience of any given day of one's vacation may powerfully shape the experience of subsequent days (Hultsman, 1998).

Along these lines, Clawson (1963) proposed five non-mutually exclusive, sequential phases of leisure experiences, including anticipation and planning, travel to the site, on-site activity, travel from the site, and recollection of the activity. Adopting this theoretical orientation with respect to vacations, we would expect future-focused savoring through anticipation to occur in the initial two stages, present-focused savoring of the moment to occur in the third stage, and past-focused savoring through reminiscence to occur primarily in the final two stages (see Clawson, 1963; Hultsman, 1998; Stewart \& Hull, 1992).

Although savoring processes, like leisure experiences, unfold over time, the essence of savoring always occurs in the here and now, as people savor the positive feelings they have either when looking ahead, looking back, or enjoying the moment (Bryant \& Veroff, 2007). And savoring these feelings takes time. For instance, when people are told to savor an experience, their dominant response is to slow down and try to make the moment last longer (Bryant \& Veroff, 2007). Type As' high levels of time urgency (e.g., Friedman \& Ulmer, 1984), however, suggest that these individuals have a low capacity to slow down and savor positive feelings. This decreased ability to savor a vacation experience could have negative consequences for Type As' wellbeing. People's beliefs about their ability to savor a vacation were positively related to their reported health and wellbeing during a long vacation, and furthermore, savoring beliefs continued to predict greater health and wellbeing one month after the vacation (De Bloom, Geurts, \& Kompier, 2012).

The present research is predicated on the assumption that Type A behavior reduces the enjoyment of leisure experiences, and that this relationship is mediated by savoring responses, or behaviors and cognitions in which people engage during positive experiences to regulate positive feelings (Bryant, 2003; Bryant, Chadwick, \& Kluwe, 2011; Bryant \& Veroff, 2007). Compared to Type Bs, Type As may react to positive events in ways that dampen enjoyment. This emphasis on the mechanisms through which Type A behavior may influence positive 
experience is consistent with past recommendations that research on Type A behavior should focus more on processes and less exclusively on outcomes in studying its associations with subjective well-being (Bryant \& Yarnold, 1990).

\subsection{Type A behavior and subjective wellbeing}

As noted above, the Type A behavior pattern is characterized by achievement-orientation, hard-driving competitiveness, speed, impatience, and aggressiveness-behaviors that may occur as a result of attempts to control stressful environments (Glass, 1977) or to reduce uncertainty about personal abilities in response to situational demands (Strube, 1987). Of particular interest in the present study is the Type A component of time urgency (i.e., "hurry sickness;" Friedman \& Ulmer, 1984; Mueser, Yarnold, \& Bryant, 1987), which compels Type As to move rapidly from situation to situation in pursuit of instrumental goals. As Friedman (1996) has argued, "Time urgency is...the major overt Type A behavior (TAB) component" (p. 25).

In the context of vacation enjoyment, time urgency might make it harder for Type As to "stop and smell the roses," live in the moment, and fully savor positive experiences (Bryant \& Veroff, 2007; Friedman \& Ulmer, 1984). Reviewing the literature on happiness, Myers (1992) concluded, "The essence of happiness is pausing to savor the gift of our present moments" (p. 203). Savoring positive experiences often involves prolonging or lingering in pleasant situations, which Type As may be less likely to do because of time urgency (Bryant \& Veroff, 2007).

In fact, previous research suggests that Type As actually find relaxation and leisure activities stressful (Friedman \& Ulmer, 1984). For instance, Type As show higher levels of adrenaline secretion and report greater distress during periods of inactivity compared to Type Bs, while Type Bs find work activities more stressful compared to Type As (Frankenhaeuser, Lundberg, \& Forsman, 1980). Type As also spend less time engaging in leisure activities, compared to Type Bs (Kirkcaldy, Shephard, \& Cooper, 1993).

Consistent with their tendency toward time urgency, Type As are also less likely to take time to recall memories and reflect on previous experiences (Friedman \& Ulmer, 1984). Bryant, Yarnold, and Morgan (1991) found that Type As were less likely to actively store memories after a positive experience in order to recall them at a later time, while Type Bs were more likely to purposefully encode memories after a pleasant event in order to reminisce about them later. However, Type As and Type Bs did not differ in how frequently they reminisced or in the particular strategies they used to reminisce about positive memories (Bryant et al., 1991).

\subsection{The multidimensionality of Type A behavior}

Most prior studies of Type A behavior and subjective wellbeing have examined only global, total score measures of Type A behavior (Bryant \& Yarnold, 1990; Strube, Berry, Goza, \& Fennimore, 1985). However, there is strong evidence that Type A behavior is multidimensional and that analyzing only global total scores may produce misleading results (Bryant \& Yarnold, 1989, 1995). In particular, using confirmatory factor analysis to examine the structure of responses to the most commonly used self-report measure of Type A behavior among college students - the Student Jenkins Activity Survey (SJAS; Glass, 1977) - Bryant and Yarnold (1989) concluded that a one-factor "total score" model provided a poor fit to the SJAS data, and that a three-factor model, consisting of correlated factors of Hard-driving Competitiveness, Rapid Eating, and Rapid Talking, best fit the data. Concerning the subjective quality of life, Harddriving Competitiveness reflects an intensely ambitious achievement orientation that might inhibit the enjoyment of leisure activities, whereas Rapid Eating and Rapid Talking reflect a 
frenetic impatience that might make it difficult to spend time savoring pleasant physical sensations or lingering in social conversations.

\subsection{Savoring and Type A behavior}

A central focus of the present study is on the construct of savoring as a process regulating enjoyment. Savoring, defined as the capacity "to attend to, appreciate, and enhance the positive experiences" in one's life (Bryant \& Veroff, 2007, p. 2), is also a multidimensional concept. Bryant and Veroff (2007) identified ten types of savoring responses, representing behaviors or cognitions in which people may engage when experiencing positive events: Sharing with Others, Memory Building, Self-Congratulation, Temporal Awareness, Behavioral Expression, Sensory-Perceptual Sharpening, Absorption, Comparing, Counting Blessings, and Kill-joy Thinking.

When savoring a positive event, people attend to the experience and become mindfully aware of their positive feelings. However, time urgency is likely to divert people's attention from ongoing positive experiences and thereby dampen savoring responses (Bryant \& Veroff, 2007). Moreoever, Type As may also be more likely to multitask in an effort to accomplish more tasks in less time (Friedman \& Ulmer, 1984). Because multitasking divides attention simultaneously across multiple unfinished tasks, as a result Type As may be less able than Type Bs to attend to positive experiences and savor the moment (Bryant \& Veroff, 2007).

The tendency of Type As not to actively store memories of positive events may also limit their savoring responses (Bryant et al., 1991). Memory building is not only related to later retrospective enjoyment, but may also lead to greater enjoyment in the present. People pay more attention to details of the experience when they are actively storing a memory of a positive event, and they may therefore enjoy and appreciate the ongoing event more fully. For these reasons, we hypothesized that impatience and time urgency, which are central components of Type A behavior, inhibit Type As' savoring responses in response to positive events, which in turn dampens their enjoyment of positive experiences.

During positive experiences, Type As, compared to Type Bs, may also engage in more dampening "kill-joy" thoughts about unfinished work-related tasks they should be doing instead. Furthermore, Type As' tendency toward perfectionism (Flett, Hewitt, Blankstein, \& Dynin, 1994) may increase their tendency to focus on faults in positive experiences, thereby undermining enjoyment.

Finally, an awareness of the fleetingness of time, as manifest in the savoring response of temporal awareness, might influence Type As differently from Type Bs. For Type Bs, on the one hand, an awareness of the scarcity of time during a vacation might make the remaining time more enjoyable, by bringing "its positive qualities to the forefront of one's attention along with a sense of motivation to make the most of it" (Kurtz, 2008, p. 1238). Given Type As' higher levels of time urgency, on the other hand, temporal awareness during a vacation might undermine their enjoyment of the moment, by reminding them of the fleetingness of leisure time, which might be better used in pursuit of work-related goals. However, it is also conceivable that an awareness of the speed with which time is passing might make leisure time less stressful for Type As, by making them feel as if they will be back at work in no time at all, thereby reducing A-B differences in vacation enjoyment. For these reasons, we examined the savoring response of temporal awareness as a potential moderator of the relationship between Type A behavior (particularly Speed/Impatience) and enjoyment. 


\subsection{Current study}

The goal of the current research was to determine whether savoring responses mediate the relationship between Type A behavior and level of vacation enjoyment. We chose to focus on vacation experiences for several reasons. First, vacations can boost positive affect and increase short-term happiness (Nawijn, 2011). As mentioned previously, however, extant research suggests that Type As compared to Type Bs may find vacations less enjoyable (e.g., Frankenhaeuser et al., 1980; Friedman \& Ulmer, 1984; Kirkcaldy et al., 1993). In addition, vacations have an extended duration that allows people to use a variety of different savoring strategies across multiple positive experiences. People may also be more focused on the present moment during their vacations than during ordinary everyday life (Bryant \& Veroff, 2007).

We expected that Type A behavior would be negatively associated with savoring responses that boost vacation enjoyment and positively associated with savoring responses that decrease vacation enjoyment. In particular, we tested five hypotheses:

Hypothesis 1: Higher Type A scores, specifically levels of Speed/Impatience, will predict lower reported levels of vacation enjoyment;

Hypothesis 2: Higher levels of Speed/Impatience will predict lower levels of amplifying savoring responses associated with enhanced enjoyment (such as Memory Building and Counting Blessings) and higher levels of dampening savoring responses associated with reduced enjoyment (such as Kill-joy Thinking);

Hypothesis 3: Amplifying savoring responses will predict higher levels of vacation enjoyment, and dampening savoring responses will predict lower levels of vacation enjoyment;

Hypothesis 4: Savoring responses will mediate the negative relationship between Type A behaviors of Speed/Impatience and vacation enjoyment; and

Hypothesis 5: The savoring response of temporal awareness will moderate the relationship between Type A behaviors of Speed/Impatience and vacation enjoyment. We expected that high levels of temporal awareness might either amplify or dampen the detrimental impact of time urgency on vacation enjoyment.

\section{Method}

\subsection{Participants and procedures}

A convenience sample of 764 undergraduates (613 females, 151 males) at a private metropolitan Midwestern university participated in this study as partial fulfillment of an introductory psychology course requirement. Although females were over-represented in this sample, no existing theory or consistent empirical evidence suggests that there are sex differences in the experience and expression of Type A behavior, particularly with respect to speed and impatience or hard-driving competitiveness. Participants were recruited to participate in a study about their thoughts, feelings, and behaviors in response to recent positive life events. Participants completed a series of questionnaires, including the Student Jenkins Activity Survey (SJAS; Glass, 1977), the Ways of Savoring Checklist (Bryant \& Veroff, 2007), and a measure of Vacation Enjoyment. Participants were then thanked and debriefed. 


\subsection{Measures}

\subsubsection{Student Jenkins Activity Survey}

The Student Jenkins Activity Survey (SJAS; Glass, 1977) is a 21-item measure designed to assess Type A behavior in college populations. The SJAS taps into three factors related to Type A behavior: Hard-driving Competitiveness, Rapid Talking, and Rapid Eating. The Hard-driving Competitiveness subscale $(\alpha=.72)$ is comprised of 11 closed-ended items (e.g., "Do most people consider you to be: Definitely hard-driving and competitive, probably hard-driving and competitive, probably more relaxed and easy going, or definitely more relaxed and easy going?"). The Rapid Talking subscale (interitem correlation: $r=.32, p<.0001$ ) includes two items, and it is a measure of impatient social responding ("When you listen to someone talking, and this person takes too long to come to the point, do you feel like hurrying them along?" and "How often do you actually 'put words into his mouth' in order to speed things up?"). The Rapid Eating subscale (interitem correlation: $r=.43, p<.0001$ ) also consists of two items ("Ordinarily, how rapidly do you eat?" and "Has your spouse or some friend ever told you that you eat too fast?").

In past research, SJAS total score and related subscales have shown acceptable internal consistency reliability and moderately to extremely high two-week test-retest stability (Yarnold \& Mueser, 1989; Yarnold, Mueser, Grau, \& Grimm, 1986). Supporting construct validity, SJAS scores correlate significantly with prospectively validated, objective measures of Type A behavior (Yarnold \& Bryant, 1988; Yarnold \& Mueser, 1989), predict behavioral differences among college students in studying and leisure activities (Ditto, 1982), and show discriminant validity in relation to measures of trait anxiety (Nielson \& Dobson, 1980).

Given that the SJAS has been used only sporadically in the past two decades, however, the question naturally arises as to whether it remains a valid measure of Type A behavior. To address this issue, we compared data from the current study with previously published measurement models and mean scores from comparative samples of college students. First, confirmatory factor analyses revealed that the three-factor measurement model reported by Bryant and Yarnold (1989) provides an excellent goodness-of-fit to the SJAS responses of our sample, $\chi^{2}(87, N=764)=335.31$, RMSEA $=.065$, SRMR $=.058, \mathrm{GFI}=.94$. Second, mean SJAS total scores in our sample were not significantly different from mean SJAS total scores in the 1987 normative sample (Yarnold, 1987), $t(4854)=1.07, p=.284$, Cohen's $d=0.04$. Third, there were no significant differences between mean scores for the SJAS subscales for our sample and a sample of 1,609 undergraduates reported by Bryant and Yarnold (1995): Hard-Driving Competitiveness, $t(2371)=1.23, p=.221, d=.05$; Rapid Eating, $t(2371)=1.87, p=.062, d=.08$; or Rapid Talking, $t(2371)=1.78, p=.075, d=.08$. Considered as a whole, the results of these three sets of analyses suggest that college students today respond to the SJAS items in the same ways college students did 15 to 25 years ago.

\subsubsection{Ways of Savoring Checklist}

The Ways of Savoring Checklist (WOSC; Bryant \& Veroff, 2007) is a 60-item measure assessing types of savoring responses and strategies that the participants use during positive experiences. The WOSC consists of a series of statements reflecting "things that people might think or do while they are going through positive events." Participants were asked to describe their most recent vacation and to complete a series of questions about how much they desired and enjoyed the experience. Participants then completed 60 items about the things they did or thought about during their vacation (e.g., "I thought about sharing the memory of this later 
with other people" and "I told myself why I didn't deserve this good thing"). Participants indicated the degree to which each statement reflected what they thought and did during their last vacation on a seven-point scale $(1=$ definitely doesn't apply and 7 = definitely applies $)$.

Bryant and Veroff (2007) reported evidence of the reliability and construct validity of 10 WOSC subscales as indicators of savoring responses predictive of people's enjoyment of positive events. These 10 WOSC subscales (and their reliabilities in the present sample) are presented in Table 2 (on page 9). Whereas Kill-joy Thinking may dampen positive experience, the other nine WOSC subscales (Sharing with Others, Memory Building, Self-congratulation, Temporal Awareness, Behavioral Expression, Sensory-perceptual Sharpening, Absorption, Comparing, Counting Blessings) reflect savoring responses that may amplify positive experience.

\subsubsection{Vacation Enjoyment}

The WOSC (Bryant \& Veroff, 2007) includes a single-item measure of the level of enjoyment that we used as the primary dependent measure in the present study. Respondents were asked to think about the last time they went on a vacation and to indicate how much they had enjoyed their vacation (e.g., "When this event occurred, how much did you enjoy it?"). Participants reported their level of enjoyment on a seven-point scale $(1=$ very little and $7=a$ great deal). Although not specifically designed to assess vacation enjoyment per se, this selfreport question has been used extensively in research on the WOSC over many years, across many different positive events, and with many different samples (see Bryant \& Veroff, 2007). Supporting the construct validity of this measure, additional data collected in the present sample for another project revealed that scores on this enjoyment item correlate positively with established measures of general happiness, positive affectivity, optimism, self-esteem, and perceived savoring capacity, and correlated negatively with symptoms of depression $(|r| \mathrm{s}>$ .10 , ps <.01). Using this single-item retrospective measure combines the multiple temporal phases of vacation enjoyment into a global assessment of the overall subjective quality of the vacation experience, just as people are often asked to make global evaluative judgments of their life as a whole (Andrews \& Withey, 1976). Although lacking the specificity and content validity of multidimensional measures of enjoyment (e.g., Kendzierski \& Decarlo, 1991; Stevens, Moget, de Greef, Lemmink, \& Rispens, 2000), such single-item measures are the most commonly used means in the research literature of assessing enjoyment (Smith, Harrison, \& Bryant, in press).

\section{Results}

Analyses were conducted to test the hypothesis that savoring responses mediate the relation between Type A behaviors and vacation enjoyment. Following Baron and Kenny's (1986) procedure for establishing mediation, the analyses were conducted in three steps: 1) test whether Type A behavior - particularly Speed/Impatience, assessed using the Rapid Talking or Rapid Eating subscales - significantly predicts lower vacation enjoyment (Hypothesis 1); 2) test whether Rapid Talking or Rapid Eating significantly predicts higher levels of amplifying savoring responses and lower levels of dampening savoring responses (Hypothesis 2); and 3) test whether savoring responses significantly predict vacation enjoyment when controlling for the effects of Rapid Talking or Rapid Eating (Hypothesis 3). Given evidence for the above linkages, we also tested the statistical significance of the hypothesized indirect effects of Type A behavior on vacation enjoyment via savoring responses (Hypothesis 4). Finally, we examined whether Temporal Awareness moderated the relation between Type A behaviors and vacation enjoyment (Hypothesis 5). 


\subsection{Hypothesis 1: Speed/Impatience as a negative predictor of vacation enjoyment}

Two separate, multiple regression analyses were conducted to test whether Type A behavior predicted less vacation enjoyment (Hypothesis 1)-first using the SJAS total score, and then using the three SJAS subscales (Hard-driving Competitiveness, Rapid Talking, Rapid Eating) together, to predict vacation enjoyment. Type A total score was only a marginally significant predictor of vacation enjoyment, $F(1,762)=3.55, p=.06, R^{2}<.01$, with higher levels of Type A behavior associated with less vacation enjoyment, $\beta=-.07, p=.06$.

When entering all three SJAS subscales simultaneously into a multiple regression as predictors of vacation enjoyment, the set of three predictors explained a small but significant proportion of variance in vacation enjoyment, $F(3,760)=3.60, p<.013, R^{2}=.01$. Confirming predictions about the impact of time urgency, only Rapid Talking showed a significant negative relationship with enjoyment when all three SJAS subscales were entered simultaneously (see Table 1). Thus, speed and impatience in social situations (Rapid Talking) was uniquely related to less vacation enjoyment, whereas eating fast and being hard-driving and competitive were not.

Table 1: Results of multiple regression analyses using Hard-driving Competitiveness, Rapid Eating, and Rapid Talking Subscales of the SJAS as simultaneous predictors of vacation enjoyment

\begin{tabular}{lccccc}
\hline Predictor (SJAS Subscales) & $\boldsymbol{B}$ & $S E_{b}$ & $\boldsymbol{\beta}$ & $\boldsymbol{t}$ & $\boldsymbol{p}<$ \\
\hline Hard-driving Competitiveness & -0.01 & .02 & -.01 & 0.10 & .93 \\
Rapid Eating & -0.05 & .02 & -.03 & 0.82 & .41 \\
Rapid Talking & -0.21 & .07 & -.11 & 2.96 & .003 \\
\hline
\end{tabular}

Note: Dependent variable $=$ Vacation Enjoyment.

\subsection{Hypothesis 2: Rapid Talking as a predictor of savoring responses}

Because the only significant link between Type A behavior and vacation enjoyment was for the SJAS subscale of Rapid Talking, we conducted further tests for mediation only for the Rapid Talking subscale. Specifically, we used the Rapid Talking subscale to predict each of the 10 Ways of Savoring subscales as potential mediators.

Supporting Hypothesis 2, Rapid Talking significantly predicted three of the WOSC savoring subscales (see Table 2 below). Specifically, higher Rapid Talking scores predicted less Memory Building, $F(1,762)=4.05, p<.044, R^{2}=.01$, less Counting Blessings, $F(1,762)=2.50, p<.008, R^{2}=$ .01 , and more Kill-joy Thinking, $F(1,762)=16.42, p<.0001, R^{2}=.02$. These three savoring subscales are thus potential mediators of the negative impact of Rapid Talking on vacation enjoyment.

\subsection{Hypothesis 3: Savoring Responses as predictors of vacation enjoyment}

We examined whether Memory Building, Counting Blessings, and Kill-joy Thinking were significant predictors of vacation enjoyment, when controlling for the effects of Rapid Talking on vacation enjoyment. First, we conducted three separate regression analyses with vacation enjoyment as the dependent variable, and one of the savoring responses (i.e., MemoryBuilding, Counting Blessings, and Kill-joy Thinking) and Rapid Talking entered into the model 
as simultaneous predictors (see Table 3 below). Together, Memory Building and Rapid Talking explained a significant amount of variance in vacation enjoyment, $F(2,761)=110.39, p<.0001$, $R^{2}=.23$. After controlling for Rapid Talking, higher Memory Building predicted greater vacation enjoyment. Counting Blessings and Rapid Talking also explained a significant amount of variance in vacation enjoyment, $F(2,761)=126.47, p<.0001, R^{2}=.25$. After controlling for Rapid Talking, Counting Blessings predicted greater vacation enjoyment. Finally, Kill-joy Thinking and Rapid Talking also explained a significant amount of variance in vacation enjoyment, $F(2,761)=64.24, p<.0001), R^{2}=.15$. After controlling for Rapid Talking, higher Killjoy Thinking scores predicted less vacation enjoyment.

Table 2: Results of individual regression analyses using rapid talking to predict savoring responses as measured by scores on the $\mathbf{1 0}$ Savoring Subscales

\begin{tabular}{|c|c|c|c|c|c|}
\hline Dependent Variable (Savoring Subscales) & $b$ & $S E_{b}$ & $\beta$ & $t$ & $p<$ \\
\hline $\begin{array}{l}\text { Sharing with Others: seeking out people with whom to } \\
\text { share an experience or telling others how much you } \\
\text { value the moment ( } 6 \text { items; } \alpha=.83 \text { ) }\end{array}$ & -0.08 & .07 & .04 & 1.21 & .23 \\
\hline $\begin{array}{l}\text { Memory Building: actively storing positive memories } \\
\text { for later recall or thinking of reminiscing later about a } \\
\text { positive event ( } 7 \text { items; } \alpha=.84 \text { ) }\end{array}$ & -0.13 & .07 & .07 & 2.01 & .044 \\
\hline $\begin{array}{l}\text { Self-congratulation: telling yourself how proud you are } \\
\text { or how impressed others must be ( } 7 \text { items; } \alpha=.82 \text { ) }\end{array}$ & -0.11 & .07 & .06 & 1.58 & .12 \\
\hline $\begin{array}{l}\text { Temporal Awareness: reminding yourself how transient } \\
\text { and fleeting the moment is ( } 5 \text { items; } \alpha=.78 \text { ) }\end{array}$ & 0.07 & .08 & .03 & 0.88 & .39 \\
\hline $\begin{array}{l}\text { Behavioral Expression: laughing, jumping up and down, } \\
\text { or making verbal sounds of appreciation ( } 6 \text { items; } \alpha= \\
\text {.73) }\end{array}$ & -0.09 & .07 & .05 & 1.23 & .22 \\
\hline $\begin{array}{l}\text { Sensory-perceptual Sharpening: focusing on certain } \\
\text { situational stimuli and blocking out others ( } 4 \text { items; } \alpha= \\
\text { 68) }\end{array}$ & 0.04 & .08 & .02 & 0.53 & .60 \\
\hline $\begin{array}{l}\text { Absorption: trying not to think, but to relax and exist } \\
\text { only in the present ( } 4 \text { items; } \alpha=.72 \text { ) }\end{array}$ & -0.13 & .07 & .07 & 1.82 & .07 \\
\hline $\begin{array}{l}\text { Comparing: contrasting your own feelings with what } \\
\text { others seem to be feeling, or comparing the present } \\
\text { situation with similar times in the past or personal } \\
\text { expectations ( } 7 \text { items; } \alpha=.66 \text { ) }\end{array}$ & 0.09 & .06 & .06 & 1.53 & .13 \\
\hline $\begin{array}{l}\text { Counting Blessings: reminding yourself of your good } \\
\text { fortune, or thinking about how lucky you are ( } 3 \text { items; } \\
\alpha=.68 \text { ) }\end{array}$ & -0.21 & .08 & .10 & 2.64 & .008 \\
\hline $\begin{array}{l}\text { Kill-joy Thinking: reminding yourself of other things } \\
\text { you should be doing, or thinking of ways in which the } \\
\text { positive event could have been better ( } 7 \text { items; } \alpha=.80 \text { ) }\end{array}$ & 0.26 & .06 & .15 & 4.05 & .0001 \\
\hline
\end{tabular}

Note. Predictor $=$ Rapid Talking subscale of the SJAS. 
Table 3: Results of multiple regression analyses testing Individual Savoring Subscales as Mediators of the Relationship between Rapid Talking and Vacation Enjoyment

\begin{tabular}{lccccc}
\hline Predictor & $\boldsymbol{B}$ & $S E_{b}$ & $\boldsymbol{\beta}$ & $\boldsymbol{t}$ & $\boldsymbol{p}$ \\
\hline $\begin{array}{l}\text { Testing Memory Building as Mediator: } \\
\quad\end{array}$ & .047 & .03 & .46 & 14.42 & .0001 \\
$\quad$ Memory Building & -.015 & .06 & -.08 & 2.52 & .012 \\
$\quad$ Rapid Talking & & & & & \\
Testing Counting Blessings as Mediator: & .42 & .03 & .49 & 15.48 & .0001 \\
$\quad$ Counting Blessings & -.12 & .06 & -.07 & 2.15 & .032 \\
$\quad$ Rapid Talking & & & & & \\
Testing Kill-joy Thinking as Mediator: & -.40 & .04 & -.37 & 10.80 & .0001 \\
$\quad$ Kill-joy Thinking & -.12 & .06 & -.06 & 1.81 & .08 \\
$\quad$ Rapid Talking & & &
\end{tabular}

Note: Dependent variable $=$ Vacation Enjoyment

Thus, all three of the Ways of Savoring subscales-Memory Building, Counting Blessings, and Kill-joy Thinking - were significant predictors of vacation enjoyment when controlling for the effects of the Rapid Talking subscale on vacation enjoyment. Considering all of these results together then, we see that Memory Building, Counting Blessings, and Kill-joy Thinking each mediated the effects of Rapid Talking on vacation enjoyment.

Entering all three mediators-Memory Building, Counting Blessings, and Kill-joy Thinking-along with Rapid Talking, as simultaneous predictors of vacation enjoyment, we found that all three savoring subscales remained statistically significant predictors of enjoyment, $F(4,759)=129.13, p<.001, R^{2}=.41$ : Memory-Building $(\beta=.29, p<.001)$; Counting Blessings $(\beta=.29, p<.001)$; and Kill-joy Thinking $(\beta=-.33, p<.001)$. Further supporting the mediating effects of savoring, the direct effect of Rapid Talking on vacation enjoyment was no longer statistically significant in the regression model $(\beta=-.02, p=.54)$. Figure 1 (below) displays the standardized regression coefficients in this mediational model.

\subsection{Hypothesis 4: Indirect effects of Rapid Talking on vacation enjoyment}

To test Hypothesis 4 systematically, we conducted bootstrap analyses of indirect effects (with 5,000 resamples), adjusting for both bias and skewness in bootstrap distributions (Mallinckrodt, Abraham, Wei, \& Russell, 2006) while examining multiple mediators simultaneously (Preacher \& Hayes, 2008), to estimate the bootstrap standard error (BSE) and 95\% bootstrap confidence interval $(B C I)$ for each relevant indirect effect. We used SPSS 16 to implement Preacher and Hayes' (2008) bootstrap macro program for testing multiple mediators. Results revealed that the indirect effect of Rapid Talking Type A behavior on vacation enjoyment was statistically significant for all three savoring mediators in this regression model: (a) Memory Building, $b=-$ $.18, B S E=.05,95 \%$ BCI $=-.09--.01$; (b) Counting Blessings, $b=-.05, B S E=.02,95 \%$ BCI $=-.10-$ .02 ; and (c) Kill-joy Thinking, $b=-.09, B S E=.02,95 \%$ BCI $=-.15--.04$. Decomposing the total effect, we found that Memory Building explained 18.4\%, Counting Blessings explained 32.4\%, and Kill-joy Thinking explained $42.3 \%$ of the total effect of Rapid Talking on vacation enjoyment. Thus, together the three savoring responses accounted for $84.7 \%$ of the effect of 
Rapid Talking Type A behavior on vacation enjoyment. Specifically, the dampening response of Kill-joy Thinking explained half of the indirect effect of Rapid Talking on vacation enjoyment, and the amplifying savoring responses of Memory Building and Counting Blessings explained the other half. In sum, our analyses strongly support the conclusion that savoring responses mediate the negative relationship between Rapid Talking and vacation enjoyment.

\section{Figure 1: Path model of the mediating effects of savoring responses on the relationship between Rapid Talking Type A behavior and vacation enjoyment.}

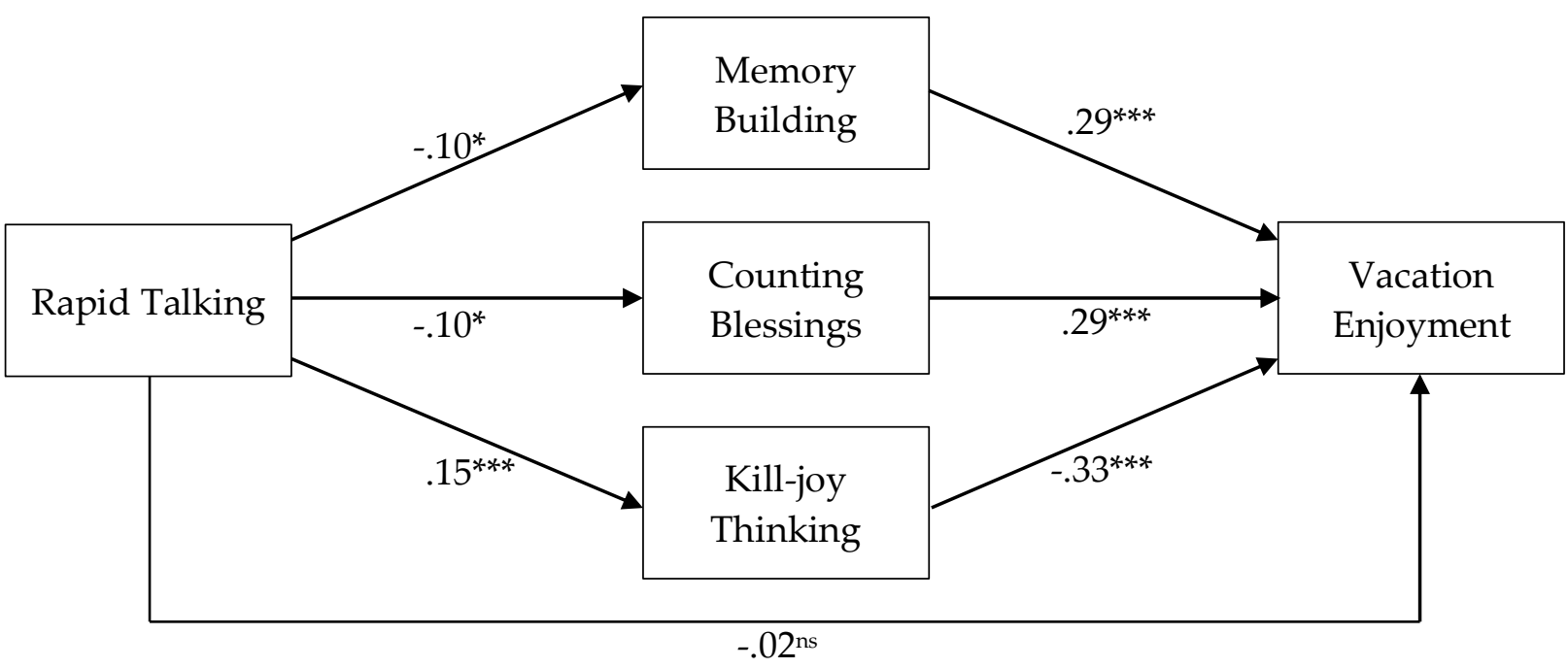

Note: Path coefficients in the diagram represent standardized regression coefficients $(N=764)$. The proportion of variance explained in each dependent variable was as follows: Memory Building $\left(R^{2}=.01\right)$; Counting Blessings $\left(R^{2}=.01\right)$; Kill-joy Thinking $\left(R^{2}=.02\right)$; Vacation Enjoyment $\left(R^{2}=.41\right) .{ }^{*} p<.05 .{ }^{* *} p<.01$. $* * *<<.001$.

Close inspection of the items constituting the 7-item Kill-joy Thinking subscale reveals two distinct types of negative savoring responses. Two Kill-joy items reflect thoughts about other things that one should be doing ("I reminded myself of other places I should be or of other things I should be doing instead"; "I thought about other things that were hanging over me, problems and worries that I still had to face"; $r=.48, p<.0001$ ); and two Kill-joy items reflect thoughts about ways in which one's ongoing experience could be better ("I thought about ways in which it could have been better"; "I told myself how it wasn't as good as I'd hoped for"; $r=$ $.48, p<.0001)$. Compared to Type Bs, Type As' greater time urgency might lead them to think more about unfinished projects looming over them during positive experiences (Friedman \& Ulmer, 1984); whereas Type As' greater perfectionism might lead them more to search for and notice aspects of positive events that are less than ideal.

To examine in greater detail these two separate facets of Kill-joy Thinking, we constructed mean scores for each pair of items and then estimated and compared the indirect effect for each of these 2-item subscales as mediators of the relationship between Rapid Talking and dampened vacation enjoyment. Whereas Rapid Talking had a significant indirect effect through Thoughts about Shortcomings of Current Experience, $b=-.10, B S E=.03,95 \%$ BCI = -.17 - -.04, the indirect effect of Rapid Talking through Thoughts about Other Things One Should be Doing was not significant, $b=-.02, B S E=.01,95 \% B C I=-.05-0.01$; and comparing these two indirect effects, the former was stronger than the latter, $Z=2.96, p=.003$. These findings 
suggest that impatience dampens vacation enjoyment among Type As by predisposing them to find faults in positive experiences more than by predisposing them to think of other things they should be doing. Extending evidence that impatience among Type As is associated with their greater perfectionism relative to Type Bs (Flett et al., 1994), our results support the notion that Type As' greater Kill-joy Thinking during vacations reflects impatience resulting from perfectionism rather than from time urgency. Assuming people are less likely to memorialize or count as blessings outcomes they see as less positive, greater perfectionistic impatience might also explain Type As' lower levels of Memory Building and Counting Blessings, relative to Type Bs.

\subsection{Hypothesis 5: Temporal Awareness as a moderator of the impact of Type A behavior on vacation enjoyment}

It is noteworthy that a heightened awareness of the passage of time, as reflected in the savoring response of Temporal Awareness, predicted higher levels of vacation enjoyment $(r=.33, p<$ .0001), but showed no significant relationship with Rapid Talking, $r=.03, p<.39$, and did not mediate the relationship between Rapid Eating and enjoyment. Supplemental regression analyses testing for a Rapid Talking x Temporal Awareness interaction following Aiken and West's (1991) procedures indicated that Temporal Awareness moderated the relationship between Rapid Talking and enjoyment, $b=0.093, S E=.043, \beta=.07, p=.03$. Probing this interaction, we found that lower levels of Temporal Awareness predicted a greater rate of decrease in vacation enjoyment as a function of Rapid Talking (see Figure 2 below). Analysis of simple slopes revealed that when level of temporal awareness was $1 S D$ below the mean, more Rapid Talking behavior predicted less enjoyment, $b=-0.37, S E=0.09, p=.026$; whereas when temporal awareness was $1 S D$ above the mean, Rapid Talking behavior was unrelated to enjoyment, $b=-0.10, S E=0.09, p=.32$. Analysis of regions of statistical significance revealed that when level of temporal awareness was more than 0.33 SD above the mean, A-B differences in vacation enjoyment were no longer significant. These results suggest that increased awareness of the passage of time reduces the negative impact of Rapid Talking on vacation enjoyment.

\section{Discussion}

The present study contributes to our understanding of the link between Type A behavior and subjective life quality in several ways. First, confirming predictions that savoring would mediate the negative relationship between Type A behavior and enjoyment, we found that Rapid Talking predicted less Memory Building, less Counting Blessings, and more Kill-joy Thinking during participants' most recent vacation; and each of these savoring responses in turn predicted vacation enjoyment. In other words, Rapid Talking predicted three types of savoring responses associated with reduced vacation enjoymentless Memory Building, less Counting Blessings, and greater Kill-joy Thinking-which together explained $85 \%$ of the negative impact of Type A behavior (in the specific form of Rapid Talking) on vacation enjoyment.

These findings replicate and extend past work linking Type A behavior to less enjoyment of vacations (e.g., Frankenhaeuser et al., 1980; Friedman \& Ulmer, 1984; Kirkcaldy et al., 1993). However, in the present study, only the Rapid Talking subscale of the SJAS significantly predicted vacation enjoyment. This result underscores the importance of adopting a multidimensional perspective in studying Type A behavior (Bryant \& Yarnold, 1989, 1995). Our findings are consistent with earlier research demonstrating that Type A behaviors of 
impatience-irritability, but not achievement striving, predict marital dissatisfaction (Barling, Bluen, \& Moss, 1990). The fact that the SJAS Rapid Talking subscale, but not the Rapid Eating or Hard-driving Competitiveness subscales, predicts savoring responses linked to less vacation enjoyment suggests social impatience rather than irritability per se underlies reduced enjoyment.

Figure 2. Scores on the Temporal Awareness savoring subscale as a moderator of the relationship between Type A Rapid Talking behavior and vacation enjoyment $(N=764)$.

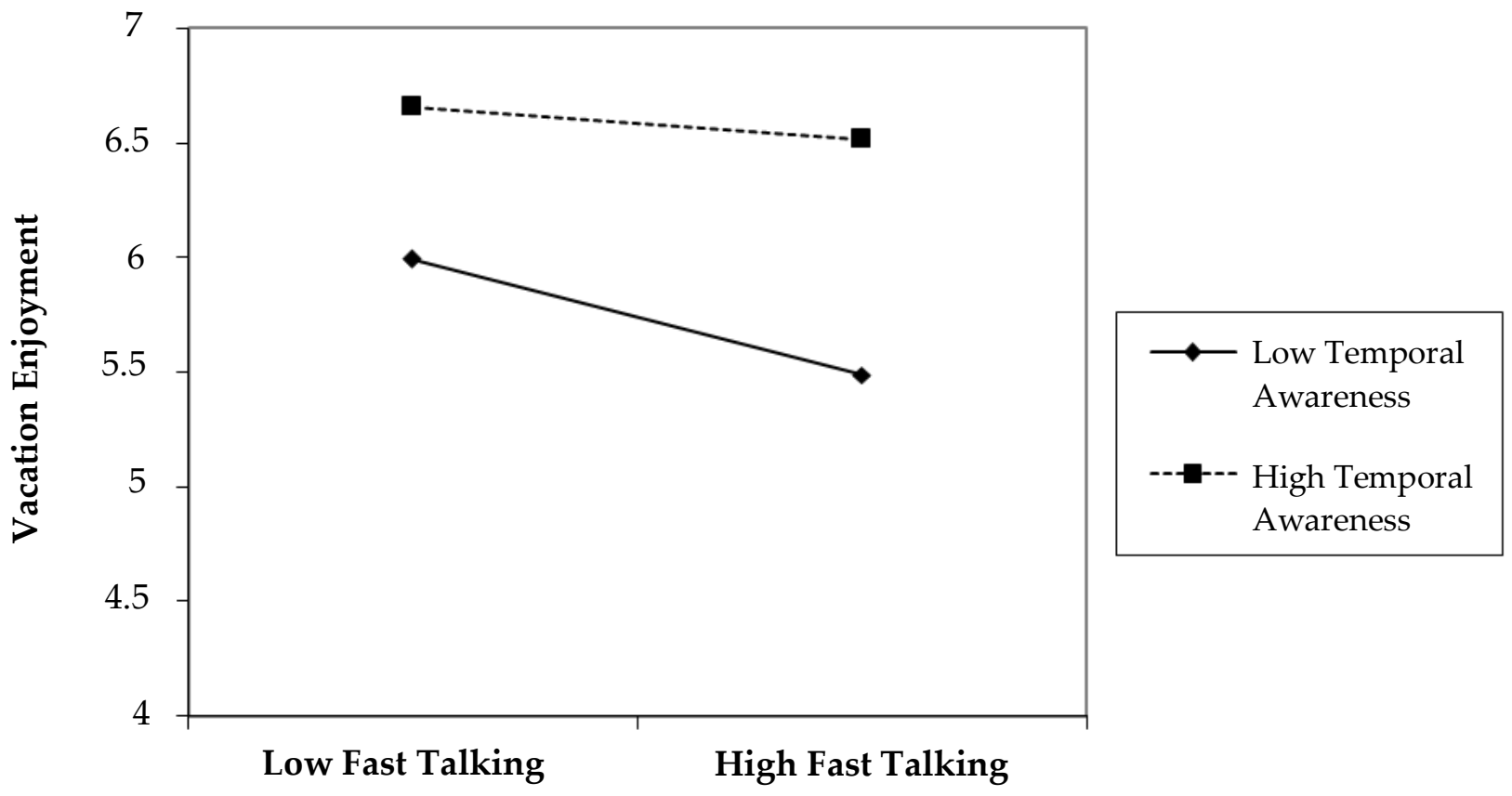

Note: Simple slopes are plotted for values of low temporal awareness that are $1 S D$ below the mean and for values of high temporal awareness that are $1 S D$ above the mean. Analysis of simple slopes revealed that when temporal awareness was low, more Rapid Talking behavior predicted less enjoyment, $b=-$ $0.37, S E=0.09, p=.026$; whereas when temporal awareness was high, Rapid Talking behavior was unrelated to enjoyment, $b=-0.10, S E=0.09, p=.32$.

With respect to savoring, this study also replicates and extends previous evidence that Type As are less likely to take the time to store memories and to reminisce about previous positive experiences (Bryant et al., 1991; Friedman \& Ulmer, 1984). Creating and storing memories are essential aspects of savoring by Memory Building and Counting Blessings. Type As appear to be more focused than Type Bs on moving ahead, and this time urgency seems to keep them from taking time to stop and appreciate positive experiences during their vacation.

Our results also shed light on the ways in which Type A behavior actively dampens the enjoyment of positive leisure experiences. Type As' greater time urgency not only predicts less memory building and counting of blessings, but also predicts higher levels of kill-joy thinking - a savoring response strongly linked to diminished appreciation (Bryant \& Veroff, 2007; Quoidbach, Berry, Hansenne, \& Mikolajczak, 2010). Our analyses indicate that Type A impatience is more strongly predictive of kill-joy thoughts about the suboptimal qualities of vacation experiences, as opposed to kill-joy thoughts about other things one should be doing. Thus, the detrimental impact of Type A impatience on enjoyment seems more closely related to perfectionism than to time urgency per se (Flett et al., 1994). 
Our data also demonstrate that the savoring response of temporal awareness moderates the detrimental impact of Type A impatience on vacation enjoyment. Although impatience was unrelated to temporal awareness, thinking about how fast time was passing and how soon one's vacation would be over weakened the negative relationship between Type A impatience and enjoyment. Given evidence that Type As find leisurely relaxation stressful (Frankenhaeuser et al., 1980; Friedman \& Ulmer, 1984), reminding oneself of the fleetingness of time may well help impatient Type As cope with the tension experienced while being away from work during vacations, thereby making this "down time" less unpleasant. In other words, temporal awareness may be a savoring strategy for Type Bs, but a coping strategy for Type As.

The present findings have direct implications for increasing Type As' vacation enjoyment. Because perfectionism appears to underlie Type As' tendency to find faults with their vacations, these maladaptive savoring responses might be preempted by interventions designed to reduce perfectionism in Type As (e.g., Friedman \& Ulmer, 1984). Moreover, Type As could be trained to avoid dampening responses and to take time to "stop and smell the roses" by adopting more amplifying savoring responses, such as memory building and counting blessings.

\section{Strengths and limitations}

This study has several limitations. Participants were not exposed to the same positive experience, but rather were instructed to focus on their most recent vacation; and Type As and Type Bs may choose to go on different types of vacations. For instance, Type As may prefer to follow a detailed itinerary jam-packed with different destinations and activities, whereas Type Bs may select more leisurely vacations. However, in the present sample, SJAS total score and Hard-driving Competitiveness, Rapid Eating, and Rapid Talking subscale scores were uncorrelated with participant reports of how long ago their vacation occurred, how long their vacation lasted, and the degree to which they were responsible for their vacation or to which their enjoyment depended on what they or others were doing, as assessed via the WOSC (Bryant \& Veroff, 2007), $|r| \mathrm{s}<.051, p s>.16$. Nevertheless, future work might hold constant the positive experience(s) investigated, to make comparisons more clearly interpretable.

We must also keep in mind that the present data are retrospective self-reports of savoring responses during one's most recent vacation. Although there is evidence that retrospective ratings of emotion contain accurate information about momentary emotional experiences (Barrett, 1997), reports of emotional intensity show pronounced biases even after a short delay (Schwarz, 2007). Empirical evidence indicates that people are prone to recall vacations as having been more pleasant than they actually experienced them at the time the vacation was unfolding (Mitchell, Thompson, Peterson, \& Cronk, 1997)-a phenomenon Mitchell and Thompson (1994) termed "rosy retrospection." However, this retrospective distortion would produce an overall exaggeration of the level of enjoyment across all respondents and would not explain the patterns of mediation and moderation we have found. Additional research is necessary to assess whether Type As and Bs actually engage in different savoring responses in "real time" while going through vacations (see Bryant et al., 2011), as well as through other positive experiences. For example, Type As may be more motivated than Type Bs to savor achievement-oriented positive events, such as winning a contest or receiving performance recognition (Bryant et al., 1991).

Additional analyses were conducted to assess whether the present pattern of findings was specific to vacations or held for another type of positive experience as well. During the present data collection, a subset of participants $(n=709)$ also completed a second version of the WOSC 
(counterbalanced for order with the version assessing the recent vacation) that measured their responses to their most recent good grade on a test or paper. In contrast to results for the most recent vacation, a multiple regression analysis revealed than none of the three SJAS subscales were significant predictors of how much participants reported enjoying the good grade, $F(3,705)=1.65, p<.18, R^{2}=.007$ : Hard-driving Competitiveness, $b=.02, S E=.09, \beta=.04, t=1.10$, $p<.27$; Rapid Eating, $b=.10, S E=.06, \beta=.07, t=1.81, p<.08$; and Rapid Talking, $b=-.04, S E=$ $.06, \beta=-.03, t=0.69, p<.49$. Nor did any of the mediating effects of savoring responses reach statistical significance. Thus, Type As and Type Bs did not differ in how much they reported enjoying their good grade, and savoring did not mediate the impact of Type A behavior on enjoyment of the good grade. Although these supplementary results do not conclusively settle the issue, they support the notion that the impact of Type A behavior on savoring and enjoyment is specific to vacations and does not apply to all positive experiences in general.

A further limitation is that we used only two items to assess rapid talking as an indicator of impatience in social settings. Future research should employ a more extensive, multi-item measure of impatience, such as the Type A Time Urgency scale developed by Wright, McCurdy, and Rogoll (1992), in predicting Type As' and Bs' responses to positive experiences. Future work might also include direct measures of perfectionism (e.g., Hewitt \& Flett, 1991), in order to distinguish high personal standards, particularly in social contexts, from the need for speed per se as a determinant of impatience. Yet, despite these limitations, the present study provides evidence that Type A behavior has important implications for the ways in which people savor positive events.

An additional limitation of this study is its cross-sectional design, which may bias the mediation analyses (Maxwell \& Cole, 2007; Maxwell, Cole, \& Mitchell, 2011). Given that a vacation, like all leisure experiences, is a process that unfolds over time, we can speculate that Type A behavior would occur throughout the vacation-during the initial stages as participants prepared for and anticipated their vacation, while they traveled to the location(s) of their vacation, and as they returned home from their vacation. Likewise, we would expect participants to engage in different forms of savoring while they anticipate, enjoy the moment, and reminisce about their vacation experiences. Moreover, we would expect there to be multiple circumstances that would elicit Type A behavior and accompanying savoring responses throughout the vacation. However, we have not assessed mediation in the future-, present-, and past-focused phases of the vacation; nor have we assessed mediation across these multiple episodes during the vacation. In order to capture better the temporal unfolding of these dynamic transactional processes, it would be better to assess cognitive, behavioral, and emotional responses longitudinally across the course of the vacation rather than just retrospectively at the end (see Madrigal, 2003; Maxwell, Cole, \& Mitchell, 2011; Stewart \& Hull, 1992). Moreover, real-time assessments of ongoing experience would be strongly preferable to retrospective reflections (Hultsman, 1998; Lee, Dattilo, \& Howard, 1994; Stewart, 1998). Although data suggest that overall leisure satisfaction is relatively stable after three months, post hoc ratings and real-time assessments are distinct constructs that provide different perspectives on subjective experience (Stewart \& Hull, 1992).

Along these lines, recent research using longitudinal experience-sampling methods with daily diary data reveals that daily positive events predict greater momentary savoring, which in turn predicts greater daily happiness (Jose, Lim, \& Bryant, 2012). Over the course of a vacation, we would expect this momentary mediation to amplify overall enjoyment of the experience as a whole. Jose et al.'s (2012) data support the validity of the conclusions we have drawn in the present study regarding the role of savoring as a mediator of vacation enjoyment. 
Our use of a single-item measure of enjoyment also limits our study. By requiring respondents to make an overall assessment of how much they enjoyed their most recent vacation as a whole, our global single-item measure of vacation enjoyment collapses across temporal domains and does not allow a fine-grained analysis of enjoyment in each phase of the unfolding vacation process. Future researchers might use multiple measures of enjoyment that focus on each of the different temporal phases of the vacation process (i.e., anticipation, savoring the moment, reminiscing), in order to enhance the reliability and content validity of the measurement of enjoyment. We would expect time urgency to produce savoring deficits in relation to all temporal phases of vacationing, as Type As rush to reach their vacation destination, fail to take time to savor the on-site activities, and hurry back to work afterwards without looking back.

Finally, we note that the size of our mediational effects is small. Together, the three Type A subscales explained only about $1 \%$ of the variance in vacation enjoyment; and, although Memory Building, Counting Blessings, and Kill-joy Thinking together explained more than 40\% of the variance in vacation enjoyment, Rapid Talking Type A behavior explained only 1-2\% of the variance in these three savoring responses. Thus, Type A social impatience reliably undermines vacation enjoyment, but to only a small degree. Nevertheless, frequent small decrements in positive affect may have a cumulative impact on wellbeing - indeed, "repeating minor but positive life events in the short-term... may be sufficient to increase well-being in the long-term" (Mochon, Norton, \& Ariely, 2008, p. 635).

\section{Authors}

Jennifer L. Smith

Loyola University of Chicago

jsmith11@luc.edu

Fred B. Bryant

Loyola University of Chicago

\section{Publishing Timeline}

Received 20 August 2012

Accepted 28 September 2012

Published 7 March 2013

\section{References}

Aiken, L. S., \& West, S. G. (1991). Multiple regression: Testing and interpreting interactions. Thousand Oaks, CA: Sage.

Andrews, F. M., \& Withey, S. B. (1976). Social indicators of well-being: Americans' perceptions of life quality. New York: Plenum Press.

Barling, J., Bluen, S., \& Moss, V. (1990). Type A behavior and martial dissatisfaction: Disentangling the effects of achievement striving and impatience-irritability. Journal of Psychology, 124, 311-319. http://dx.doi.org/10.1080/00223980.1990.10543226

Baron, R. M., \& Kenny, D. A. (1986). The moderator-mediator variable distinction in social psychological research: Conceptual, strategic, and statistical considerations. Journal of Personality and Social Psychology, 51, 1173-1182. http://dx.doi.org/10.1037/0022-3514.51.6.1173

Barrett, L. F. (1997). The relationship among momentary emotion experiences, personality descriptions, and retrospective ratings of emotion. Personality and Social Psychology Bulletin, 23, 1100-1110. http://dx.doi.org/10.1177/01461672972310010 
Bryant, F. B. (2003). Savoring Beliefs Inventory (SBI): A scale for measuring beliefs about savouring. Journal of Mental Health, 12, 175-196. http://dx.doi.org/10.1080/0963823031000103489

Bryant, F. B., Chadwick, E. D., \& Kluwe, K. (2011). Understanding the processes that regulate positive emotional experience: Unsolved problems and future directions for theory and research on savoring. International Journal of Wellbeing, 1, 107-126. http://dx.doi.org/10.5502/ijw.v1i1.18

Bryant, F. B., \& Veroff, J. (2007). Savoring: A new model of positive experience. Mahwah, NJ: Lawrence Erlbaum Associates.

Bryant, F. B., \& Yarnold, P. R. (1989). A measurement model for the student version of the Jenkins Activity Survey. Journal of Personality Assessment, 53, 188-191 http://dx.doi.org/10.1207/s15327752jpa5301_21

Bryant, F. B., \& Yarnold, P. R. (1990). The impact of Type A Behavior on subjective life quality: Bad for the heart, good for the soul? Journal of Social Behavior and Personality, 5, 369-404.

Bryant, F. B., \& Yarnold, P. R. (1995). Comparing five alternative factor-models of the Student Jenkins Activity Survey: Separating the wheat from the chaff. Journal of Personality Assessment, 64, 145-158. http://dx.doi.org/10.1207/s15327752jpa6401_10

Bryant, F. B., Yarnold, P. R., \& Morgan, L. (1991). Type A Behavior and reminiscence in college undergraduates. Journal of Research in Personality, 25, 418-433. http://dx.doi.org/10.1016/00926566(91)90031-K

Clawson, M. (1963). Land and water for recreation. Chicago: Rand McNally. PMid:14021632

Clawson, M., \& Knetsch, J. (1966). Economics of outdoor recreation. Baltimore, MD: Johns Hopkins University Press.

de Bloom, J., Guerts, S. A. E., \& Kompier, M. A. J. (2012). Vacation (after-) effects on employee health and well-being, and the role of vacation activities, experiences and sleep. Journal of Happiness Studies. http://dx.doi.org/10.1007/s10902-012-9345-3

Ditto, W. B. (1982). Daily activities of college students and the construct validity of the Jenkins Activity Survey. Psychosomatic Medicine, 44, 537-543. PMid:7163457

Flett, G. L., Hewitt, P. L., Blankstein, K. R., \& Dynin, C. B. (1994). Dimensions of perfectionism and Type A behaviour. Personality and Individual Differences, 16, 477-485. http://dx.doi.org/10.1016/01918869(94)90073-6

Frankenhaeuser, M., Lundberg, U., \& Forsman, L. (1980). Note on arousing Type A persons by depriving them of work. Journal of Psychosomatic Research, 24, 45-47. http://dx.doi.org/10.1016/00223999(80)90075-6

Friedman, M. (1996). Type A behavior: Its diagnosis and treatment. New York: Plenum.

Friedman, M., \& Rosenman, R. H. (1959). Association of specific overt behavior pattern with blood and cardiovascular findings. Journal of the American Medical Association, 169, 1286-1296. http://dx.doi.org/10.1001/jama.1959.03000290012005

Friedman, M., \& Rosenman, R. H. (1974). Type A behavior and your heart. New York: Knopf.

Friedman, M., \& Ulmer, D. (1984). Treating Type A behavior and your heart. New York: Fawcett.

Glass, D. C. (1977). Behavior patterns, stress, and coronary disease. New York: Lawrence Erlbaum Associates.

Haynes, S., Feinleib, M., \& Kannel, W. B. (1980). The relationship of psychosocial factors to coronary heart disease in the Framingham Study. III. Eight-year incidence of coronary heart disease. American Journal of Epidemiology, 111, 37-58.

Hewitt, P. L., \& Flett, G. L. (1991). Perfectionism in the self and social contexts: Conceptualization, assessment, and association with psychopathology. Journal of Personality and Social Psychology, 60, 456-470. http://dx.doi.org/10.1037/0022-3514.60.3.456

Hultsman, W. (1998). The multi-day, competitive leisure event: Examining satisfaction over time. Journal of Leisure Research, 30, 472-497.

Jose, P. E., Lim, B. T., \& Bryant, F. B. (2012). Does savoring increase happiness? A daily diary study. Journal of Positive Psychology, 7, 176-187. http://dx.doi.org/10.1080/17439760.2012.671345

Kendzierski, D., \& Decarlo, K. J. (1991). Physical activity enjoyment scale - two validation studies. Journal of Sport and Exercise Psychology, 13, 50-64. 
Kirkcaldy, B. D., Shephard, R. J., \& Cooper, C. L. (1993). Relationships between Type A behaviour, work, and leisure. Personality and Individual Differences, 15, 69-74. http://dx.doi.org/10.1016/01918869(93)90042-2

Kurtz, J. L. (2008). Looking to the future to appreciate the present: The benefits of perceived temporal scarcity. Psychological Science, 19, 1238-1241. http://dx.doi.org/10.1111/j.1467-9280.2008.02231.x

Lee, Y., Dattilo, J., \& Howard, D. (1994). The complex and dynamic nature of leisure experience. Journal of Leisure Research, 26, 195-211.

Madrigal, R. (2003). Investigating an evolving leisure experience. Antecedents and consequences of spectator affect during a live sporting event. Journal of Leisure Research, 35, 23-48.

Mallinckrodt, B., Abraham, W. T., Wei, M., \& Russell, D. W. (2006). Advances in testing the statistical significance of mediation effects. Journal of Counseling Psychology, 53, 372-378. http://dx.doi.org/10.1037/0022-0167.53.3.372

Maxwell, S. E., \& Cole, D. A. (2007). Bias in cross-sectional analyses of longitudinal mediation. Psychological Methods, 12, 23-44. http://dx.doi.org/10.1037/1082-989X.12.1.23

Maxwell, S. E., Cole, D. A., \& Mitchell, M. A. (2011). Bias in cross-sectional analyses of longitudinal mediation: Partial and complete mediation under an autoregressive model. Multivariate Behavioral Research, 46, 816-841. http://dx.doi.org/10.1080/00273171.2011.606716

Mitchell, T., \& Thompson, L. (1994). A theory of temporal adjustments of the evaluation of events: Rosy prospection and rosy retrospection. In C. Stubbart, J. Porac, \& J. Meindl (Eds.), Advances in managerial cognition and organizational information-processing (Vol. 5, pp. 85-114). Greenwich, CT: JAI Press.

Mitchell, T. R., Thompson, L., Peterson, E., \& Cronk, R. (1997). Temporal adjustments in the evaluation of events: The "rosy view." Journal of Experimental Social Psychology, 33, 421-448. http://dx.doi.org/10.1006/jesp.1997.1333

Mochon, D., Norton, M. I., \& Ariely, D. (2008). Getting off the hedonic treadmill, one step at a time: The impact of regular religious practice and exercise on well-being. Journal of Economic Psychology, 29, 632-642. http://dx.doi.org/10.1016/j.joep.2007.10.004

Mueser, K. T., Yarnold, P. R., \& Bryant, F. B. (1987). Type A behavior and time urgency: Perception of time adjectives. British Journal of Medical Psychology, 60, 267-269. http://dx.doi.org/10.1111/j.20448341.1987.tb02740.x

Myers, D. G. (1992). The pursuit of happiness: Who is happy - and why. New York: William Morrow.

Myrtek, M. (2001). Meta-analyses of prospective studies on coronary heart disease, Type A personality, and hostility. International Journal of Cardiology, 70, 245-251. http://dx.doi.org/10.1016/S01675273(01)00441-7

Nawijn, J. (2011). Happiness through vacationing: Just a temporary boost or long-term benefits? Journal of Happiness Studies, 12, 651-665. http://dx.doi.org/10.1007/s10902-010-9221-y

Nielson, W. R., \& Dobson, K. S. (1980). The coronary-prone behavior pattern and trait anxiety: Evidence for discriminant validity. Journal of Consulting and Clinical Psychology, 48, 546-547. http://dx.doi.org/10.1037/0022-006X.48.4.546

Preacher, K. J., \& Hayes, A. F. (2008). Asymptotic and resampling strategies for assessing and comparing indirect effects in multiple mediator models. Behavior Research Methods, 40, 879-891. http://dx.doi.org/10.3758/BRM.40.3.879

Quoidbach, J., Berry, E. V., Hansenne, M., \& Mikolajczak, M. (2010). Positive emotion regulation and well-being: Comparing the impact of eight savoring and dampening strategies. Personality and Individual Differences, 49, 368-373. http://dx.doi.org/10.1016/j.paid.2010.03.048

Ragland, D. R., \& Brand, R. J. (1988). Type A behavior and mortality from coronary heart disease. New England Journal of Medicine, 318, 65-69. http://www.nejm.org/doi/full/10.1056/NEJM198801143180201

Samuel, W., \& McClure, F. S. (2002). Type A personality. In W. E. Craighead \& C. B. Nemeroff (Eds.), Corsini Encyclopedia of Psychology and Behavioral Science (Vol. 4, pp. 1721-1722). New York: Wiley.

Schwarz, N. (2007). Retrospective and concurrent self-reports: The rationale for real-time data capture. In A. A. Stone, S. S. Shiffman, A. Atienza, \& L. Nebeling (Eds.), The science of real-time data capture: Selfreports in health research (pp. 11-26). New York: Oxford University Press. 
Smith, J. L., Harrison, P. R., \& Bryant, F. B. (in press). Enjoyment. In A. C. Michalos (Ed.), Encyclopedia of quality of life research. New York: Springer.

Stevens, M., Moget, P., de Greef, M. H. G., Lemmink, K., \& Rispens, P. (2000). The Groningen Enjoyment Questionnaire: A measure of enjoyment in leisure-time physical activity. Perceptual and Motor Skills, 90, 601-604. http://dx.doi.org/10.2466/pms.2000.90.2.601

Stewart, W. P. (1998). Leisure as multiphase experiences: Challenging traditions. Journal of Leisure Research, 30, 391-400.

Stewart, W., \& Hull, R. (1992). Satisfaction of what? Post hoc versus real-time construct validity. Leisure Sciences, 14, 195-209. http://dx.doi.org/10.1080/01490409209513168

Strube, M.J. (1987). A self-appraisal model of the Type A behavior pattern. In R. Hogan \& W. Jones (Eds.), Perspectives in personality theory (Vol. 2, pp. 201-250). Greenwich, CT: JAI Press.

Strube, M. J., Berry, J. M., Goza, B. K., \& Fennimore, D. (1985). Type A behavior, age, and psychological well-being. Journal of Personality and Social Psychology, 49, 203-218. http://dx.doi.org/10.1037/00223514.49.1.203

Wright, L., McCurdy, S., \& Rogoll, G. (1992). The TUPA scale: A self-report measure for the Type A subcomponent of time urgency and perpetual activation. Psychological Assessment, 4, 352-356. http://dx.doi.org/10.1037/1040-3590.4.3.352

Yarnold, P. R. (1987). Norms for the Glass Model of the short SJAS. Social and Behavioral Sciences Documents, 16, 60-65.

Yarnold, P. R., \& Bryant, F. B. (1988). A note on measurement issues in Type A research: Let's not throw out the baby with the bath water. Journal of Personality Assessment, 52, 410-419. http://dx.doi.org/10.1207/s15327752jpa5203_2

Yarnold, P. R., \& Mueser, K. T. (1989). Meta-analyses of the reliability of Type A behaviour measures. British Journal of Medical Psychology, 62, 43-50. http://dx.doi.org/10.1111/j.2044-8341.1989.tb02809.x

Yarnold, P. R., Mueser, K. T., Grau, B. W., \& Grimm, L. G. (1986). The reliability of the student version of the Jenkins Activity Survey. Journal of Behavioral Medicine, 9, 401-414.

http://dx.doi.org/10.1007/BF00845123 